\title{
Pengaruh Model Pembelajaran Contextual Teaching and Learning (CTL) Berbantuan LKS terhadap Hasil Belajar Fisika Siswa SMA Attohiriyah Bodak
}

\author{
Syamsul Hakim $^{\left.1^{*}\right)}$, Wahyudi ${ }^{2)}$, Ni Nyoman Sri Putu Verawati ${ }^{3)}$ \\ ${ }^{1,2 \& 3)}$ Program Studi Pendidikan Fisika Universitas Mataram \\ *Email:syamsulhakim07@gmail.com
}

Article History

Received: April 2018

Reviewed: May 2018

Published: June 2018

Key Words

Contextual Teaching and

Learning;

Student's Worksheets;

Study outcomes

\section{Sejarah Artikel}

Diterima: April 2018

Direviu: Mei 2018

Dipublikasi: Juni 2018

Kata Kunci:

Pembelajaran

Kontekstual;

Lembar Kerja Siswa;

Hasil Belajar

How to cite this article?

\begin{abstract}
[Title: The Effect of Contextual Teaching and Learning (CTL) Model with Student Worksheet Assistance toward Physics Learning Outcomes of Attohiriyah Bodak High School Students]. This research aims to determine the influence of Contextual Teaching and Learning model with student worksheets toward student's physics study result at SMA Attohiriyah Bodak in academic year 2015/2016. The type of this research was quasi-experiment with nonequivalent control group design. The population in this research were all students in $X$ grade SMA Attohiriyah Bodak with amount student 149 spread out into 6 class. The sample of this research is $X B$ as experiment class and $X E$ as control class were drawn by purposive sampling. The study result obtained was analysis with t-test separated varians, and the results showed $t_{\text {count }}=3.78$ and $t_{\text {table }}=2.01$ in significant standard $5 \%$ and released standard 5. Because Ho rejected and Ha accepted. So, we can conclude that contextual teaching and learning model with student worksheets positive influence toward student's physics study result at SMA Attohiriyah Bodak academic year 2015/2016.
\end{abstract}

\begin{abstract}
Abstrak
Penelitian ini bertujuan untuk mengetahui pengaruh model pembelajaran Contextual Teaching and Learning (CTL) berbantuan LKS terhadap hasil belajar fisika siswa SMA Attohiriyah Bodak tahun pelajaran 2015/2016. Jenis penelitian ini adalah penelitian quasi eksperimen dengan desain penelitian nonequivalent control group design. Populasi dari penelitian ini adalah seluruh siswa kelas X SMA Attohiriyah Bodak berjumlah 149 siswa yang tersebar dalam enam kelas. Sampel penelitian ini adalah kelas XB sebagai kelas eksperimen dan XE sebagai kelas kontrol yang dipilih menggunakan teknik Purposive Sampling. Hasil belajar dianalisis menggunakan uji-t Separated Varians, diperoleh $t_{\text {hitung }}$ sebesar 3,78 dan $t_{\text {tabel }}$ sebesar 2,01 pada taraf signifikan 5\% dan derajat kebebasan 5. Oleh karena $t_{\text {hitung }}>t_{\text {tabel }}$, maka Ho ditolak dan Ha diterima. Jadi, dapat disimpulkan bahwa model pembelajaran CTL berbantuan LKS berpengaruh positif terhadap hasil belajar fisika siswa SMA Attohiriyah Bodak tahun pelajaran 2015/2016.
\end{abstract}

Hakim, S., Wahyudi., Verawati, N., N., S., P. (2018). Pengaruh Model Pembelajaran Contextual Teaching and Learning (CTL) Berbantuan LKS terhadap Hasil Belajar Fisika Siswa SMA Attohiriyah Bodak. Lensa: Jurnal Kependidikan Fisika, 6(1), 1-7.

\section{PENDAHULUAN}

Pelaksanaan pendidikan yang bermutu merupakan suatu upaya yang dapat dilakukan untuk menyiapkan sumber daya manusia yang berkualitas dalam menghadapi tantangan yang semakin kompleks (Trianto, 2010). Pendidikan termasuk di dalamnya ilmu pengetahuan alam (IPA) yang telah dikenal oleh siswa sejak masih di Sekolah Dasar (SD). Pada jenjang Sekolah Menengah Pertama (SMP), siswa mulai mengenal IPA terpadu yang terdiri dari IPA fisika dan 
IPA biologi. Pada jenjang Sekolah Menengah Atas (SMA), IPA secara lebih khusus terdiri dari fisika, biologi, dan kimia.

Pembelajaran IPA khususnya fisika diharapkan mampu untuk menyiapkan SDM yang mampu bersaing di era global melalui pelaksanaan pembelajaran yang tidak hanya proses penerimaan informasi sebab IPA bukan hanya sekedar penguasaan kumpulan pengetahuan berupa fakta-fakta, konsep-konsep, atau prinsip-prinsip saja tetapi juga merupakan suatu proses penemuan dari hasil penyelidikan (Badan Standar Isi [BSI], 2006). Kenyataan yang terjadi di sekolah adalah banyak siswa yang kurang antusias dalam mengikuti pembelajaran, sebab mereka menganggap bahwa pelajaran fisika adalah sebatas pelajaran di bangku sekolah yang tidak ada kaitannya dalam kehidupan sehari-hari yang tidak ada hubungannya dengan fenomenafenomena dalam kehidupan sehari-hari, akibatnya hasil belajar fisika siswa rendah. Tabel 1 menunjukkan nilai rata-rata ulangan semester ganjil kelas X SMA Attohiriyah Bodak tahun pelajaran 2015/2016.

Tabel 1. Nilai Rata-rata Ulangan Semester Ganjil Kelas X SMA Attohiriyah Bodak tahun pelajaran 2015/2016.

\begin{tabular}{ccc}
\hline \multicolumn{1}{l}{ Kelas } & Jumlah Siswa & Nilai Rata-rata \\
\hline $\mathrm{XA}$ & 24 & 64,13 \\
\hline $\mathrm{XB}$ & 26 & 65,04 \\
\hline $\mathrm{XC}$ & 22 & 63,14 \\
\hline $\mathrm{XD}$ & 24 & 66,00 \\
\hline $\mathrm{XE}$ & 26 & 65,07 \\
\hline $\mathrm{XF}$ & 27 & 64,07 \\
\hline
\end{tabular}

Permasalahan di atas dapat diatasi dengan cara mengubah cara pandang siswa yang menganggap pelajaran fisika tidak ada kaitan dan manfaatnya dalam kehidupan sehari-hari. Salah satu upaya untuk mengaitkan pelajaran dengan kehidupan adalah melalui pembelajaran kontekstual (Contextual Teaching and Learning).

Contextual Teaching and Learning (CTL) adalah sebuah sistem yang merangsang otak untuk menyusun pola-pola yang mewujudkan makna. CTL adalah sebuah sistem pengajaran yang cocok dengan otak karena menghasilkan makna dengan menghubungkan muatan akademis dengan konteks dari kehidupan sehari-hari siswa (Johnsons, 2014).

Pelaksanaan pembelajaran dengan model kontekstual diharapkan siswa lebih aktif, dalam arti proses pembelajaran berorientasi student-centered. Untuk mewujudkan harapan tersebut, maka peneliti menggunakan bantuan LKS yang diharapkan dapat membantu siswa dalam melakukan kegiatan penyelidikan. Penelitian ini bertujuan untuk mengetahui pengaruh model pembelajaran Contextual Teaching and Learning (CTL) berbantuan LKS terhadap hasil belajar fisika siswa SMA Attohiriyah Bodak tahun pelajaran 2015/2016.

\section{METODE}

Penelitian ini adalah penelitian eksperimen semu (quasi experimental). Populasi penelitian ini adalah siswa kelas X SMA Attohiriyah Bodak tahun pelajaran 2015/2016 yang berjumlah 149 orang yang tersebar dalam enam kelas. Dari keenam kelas tersebut diambil kelas XB sebagai kelas eksperimen dan kelas XE sebagai kelas kontrol yang dipilih secara purposive sampling sebab jumlah siswa kedua kelas sama dan nilai rata-rata kedua kelas hamper sama.

Rancangan penelitian yang digunakan pada penelitian ini adalah non equivalent control group design yang dilakukan dengan cara memberikan pre-test kepada kelas eksperimen dan kelas kontrol untuk mengetahui kemampuan awal kedua kelas. Setelah diberikannya tes awal baru diberikan perlakuan model pembelajaran CTL berbantuan LKS untuk kelas eksperimen dan pembelajaran konvensional untuk kelas kontrol (Setyosari, 2010).

Data yang diperoleh dari hasil pre-test diuji normalitas dengan uji chi-quadrat dan diuji homogenitasnya dengan uji-f. Sedangkan untuk hasil post-test digunakan untuk menguji hipotesis penelitian dengan menggunakan uji-t. 


\section{HASIL DAN PEMBAHASAN}

Data penelitian diperoleh dari hasil pre-test dan post-test. Data yang diperoleh dari pre-test dapat digunakan untuk mengetahui kemampuan awal yang dimilki kelas eksperimen dan kelas kontrol sebelum dilaksanakan pembelajaran. Sedangkan data yang diperoleh dari post-test digunakan untuk melihat pengaruh dari model pembelajaran CTL berbantuan LKS terhadap hasil belajar siswa. Gambar 1 menunjukkan representasi hasil pre-test kelas eksperimen dan kelas kontol.

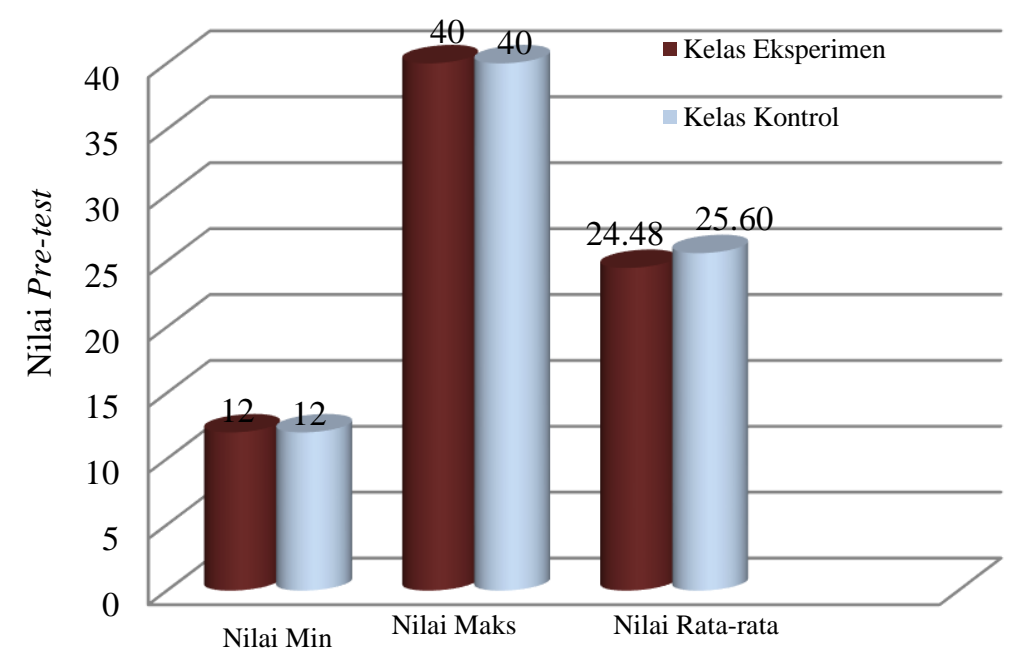

Gambar 1. Perbandingan Nilai Pre-test Kelas Eksperimen dan Kelas Kontrol

Berdasarkan Gambar 1 di atas, tampak bahwa perolehan nilai kelas eksperimen dan kelas kontrol masih rendah karena pada kedua kelas belum dilaksanakan pembelajaran. Setelah dilaksanakan pembelajaran nilai yang diperoleh kedua kelas mengalami peningkatan. Gambar 2 menunjukkan representasi hasil post-test kelas eksperimen dan kelas kontrol.

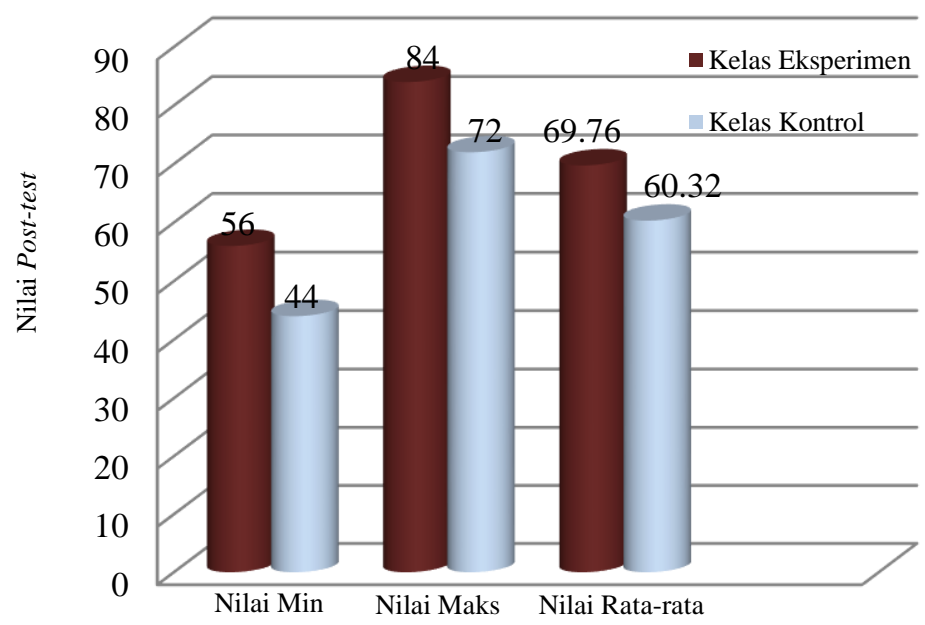

Gambar 2. Perbandingan Nilai Post-test Kelas Eksperimen dan Kelas Kontrol

Berdasarkan Gambar 2 di atas, terlihat bahwa perolehan nilai kelas eksperimen lebih tinggi dibandingkan kelas kontol. Jika gambar 1 dan gambar 2 dibandingkan, peningkatan nilai yang diperoleh kelas eksperimen lebih tinggi daripada nilai kelas kontrol. Nilai rata-rata hasil pre-test kelas eksperimen dan kelas kontrol berturut-turut yakni 24,48 dan 25,60. Nilai rata-rata hasil post-test kelas eksperimen dan kelas kontrol berturut-turut yakni 69,76 dan 60,32.

Berdasarkan perolehan data di atas, memperlihatkan bahwa kelas eksperimen yang diberikan perlakuan model pembelajaran CTL berbantuan LKS memiliki kemampuan akhir 
lebih tinggi daripada kelas kontrol, karena siswa pada kelas eksperimen lebih aktif pada saat pembelajaran dan dapat menghubungkan langsung materi yang dipelajari dengan fenomena dalam kehidupan sehari-hari sesuai dengan karakteristik model pembelajaran CTL. Pembelajaran CTL bermakna sebab proses pembelajarannya menghubungkan muatan akademis dengan konteks dari kehidupan sehari-hari siswa (Johnsons, 2014). Pada penelitian ini juga, digunakan LKS sebagai bantuan dalam pembelajaran dan hal ini sangat efektif membantu siswa dalam kegiatan penyelidikan fenomena yang terkait dengan materi kalor dalam kehidupan sehari-hari sehingga dapat menggiring siswa menghubungkan langsung materi dengan fenomena-fenomena kalor dalam kehidupan sehari-hari, sebab LKS yang digunakan memuat sekumpulan kegiatan mendasar yang dilakukan siswa untuk memaksimalkan pemahaman. Hal ini dapat memperkuat penguasaan siswa terhadap materi kalor yang dipelajari dan dapat membantu siswa menyelesaikan permasalahan-permasalahan fisika yang lebih kompleks sehingga hasil belajar fisika siswa meningkat.

Peningkatan hasil belajar yang diperoleh pada hasil penelitian ini juga didukung oleh penelitian sebelumnya (Hayati dkk., 2013; Gafrani \& Mulyanratna, 2013). Peningkatan ini terjadi sebab salah satu tahapan dalam pembelajaran CTL menuntut siswa untuk melakukan penyelidikan secara langsung, dengan adanya proses penyelidikan tersebut, diharapkan siswa memperoleh pengalaman langsung mengenai materi yang dipelajari sehingga dapat membantu siswa dalam menyelesaikan permasalahan-permasalahan fisika yang ditemukan dengan pengalaman yang didapatkan siswa saat pelaksanakan penyelidikan.

Pelaksanaan penyelidikan yang dilakukan oleh siswa tentu tidak terlepas dari bimbingan guru. Agar pelaksanaan penyelidikan yang dilakukan lebih terarah, maka digunakan bantuan LKS yang berisi langkah-langkah dalam melakukan penyelidikan mengenai fenomena-fenomena fisika khususnya tentang kalor yang terdapat dalam kehidupan sehari-hari. Penggunaan bantuan LKS juga sangat membantu mewujudkan pembelajaran

sesuai dengan karakteristik dari pembelajaran CTL bahwa pengetahuan dan keterampilan siswa diperoleh dari usaha siswa mengkonstruksi sendiri pengetahuan dan keterampilan barunya (Sugiyanto, 2010). Berbeda dengan pembelajaran konvensional, pembelajarannya cendrung di dominasi oleh guru sehingga aktivitas siswa kurang dan yang terjadi adalah proses transfer ilmu tanpa ada kegiatan yang memberikan pengalaman langsung kepada siswa sehingga memberikan dampak siswa cendrung menghafal. Namun, bukan berarti pembelajaran konvensional tidak baik buktinya bahwa kelas kontrol yang diberi perlakuan pembelajaran konvensional juga mengalami peningkatan hasil belajar, supaya pembelajaran lebih maksimal maka perlu memilih model pembelajaran yang sesuai dengan karakteristik dari materi tersebut seperti pada materi kalor yang sangat sering dijumpai aplikasinya dalam kehidupan sehari-hari alangkah baiknya siswa diberikan kesempatan langsung untuk melakukan penyelidikan agar siswa dapat mengetahui hubungan langsung materi yang dipelajari dengan keadaan nyata di sekitar siswa yakni model pembelajaran CTL berbantuan LKS.

Adanya pengaruh model pembelajaran CTL berbantuan LKS sebab pelaksanaan pembelajaran model CTL berbantuan LKS melalui tahapan-tahapan yang sistematis yang meliputi tahap konstruktivisme, tahap inkuiri, tahap bertanya, tahap masyarakat belajar, tahap pemodelan, tahap refleksi, dan tahap penilaian sebenarnya.

1. Tahap konstruktivisme

Pada tahapan ini, siswa dijelaskan tujuan pembelajaran yang harus dicapai dan pengetahuan siswa tentang materi kalor mulai dibangun melalui pertanyaan tentang fenomena-fenomena kalor dalam kehidupan sehari-hari sehingga timbul pada pemikiran siswa bahwa materi kalor sangat erat kaitannya dalam kehidupan sehari-hari dan antusias untuk mempelajarinya.

2. Tahap inkuiri

Pada tahapan ini, siswa diarahkan untuk melakukan penyelidikan secara berkelompok terkait dengan materi kalor yang sering dijumpai siswa dalam kehidupan sehari-hari sesuai dengan langkah-langkah yang telah disiapkan dalam LKS.

3. Tahap bertanya 
Setelah melakukan penyelidikan, siswa diarahkan untuk menjawab pertanyaanpertanyaan yang telah disiapkan dalam LKS yang dapat membantu siswa menemukan konsep-konsep kalor dalam kehidupan sehari-hari.

4. Tahap masyarakat belajar

Pada tahapan ini, salah satu perwakilan kelompok diberikan kesempatan untuk mempresentasikan hasil penyelidikan kelompok di depan dan kelompok lain mennggapi sehingga siswa memperoleh sendiri konsep-konsep yang sesuai dengan fenomena-fenomena yang mereka temukan dalam penyelidikan.

5. Tahap pemodelan

Konsep-konsep yang masih belum dipahami siswa selanjutnya dijelaskan guru bagaimana keadaan nyatanya melalui fenomena-fenomena dalam kehidupan sehari-hari.

6. Tahap refleksi

Pada tahap ini, siswa dibimbing untuk menyimpulkan hasil penyelidikan yang telah dilakukan sekaligus memberikan penghargaan kepada kelompok yang terbaik. Dengan diberikannya penghargaan dapat menumbuhkan antusias siswa untuk mengikuti pelajaran pada pertemuan berikutnya.

7. Tahap penilaian sebenarnya

Penilaian yang dilakukan tidak hanya pada hasil belajar yang diperoleh siswa setelah pelaksanaan pembelajaran saja, namun penilaian juga dilakukan pada proses pembelajaran berlangsung. Dengan adanya penilaian pada proses pembelajaran ini, siswa akan lebih maksimal dalam mengikuti pelajaran sehingga dapat terlihat langsung kemampuan siswa dalam bersikap (afektif) dan kemampuannya dalam melakukan penyelidikan (psikomotor).

Pembelajaran yang dilakukan dengan model CTL berbantuan LKS tentu sangat berbeda jika dibandingkan dengan pembelajaran konvensional. Pada pembelajaran CTL berbantuan LKS hasil belajar yang diperoleh siswa tidak hanya kognitif dan afektif, namun dapat juga dilihat kemampuan psikomotor siswa. Sedangkan pembelajaran konvensional hanya melihat hasil belajar ranah kognitif dan afektif tanpa melihat kemampuan psikomotor siswa sebab pelaksanaan pembelajarannya lebih didominasi kegiatan guru. Representasi hasil belajar ranah psikomotor kelas eksperimen dan kelas kontrol disajikan secara sederhana pada Gambar 3.

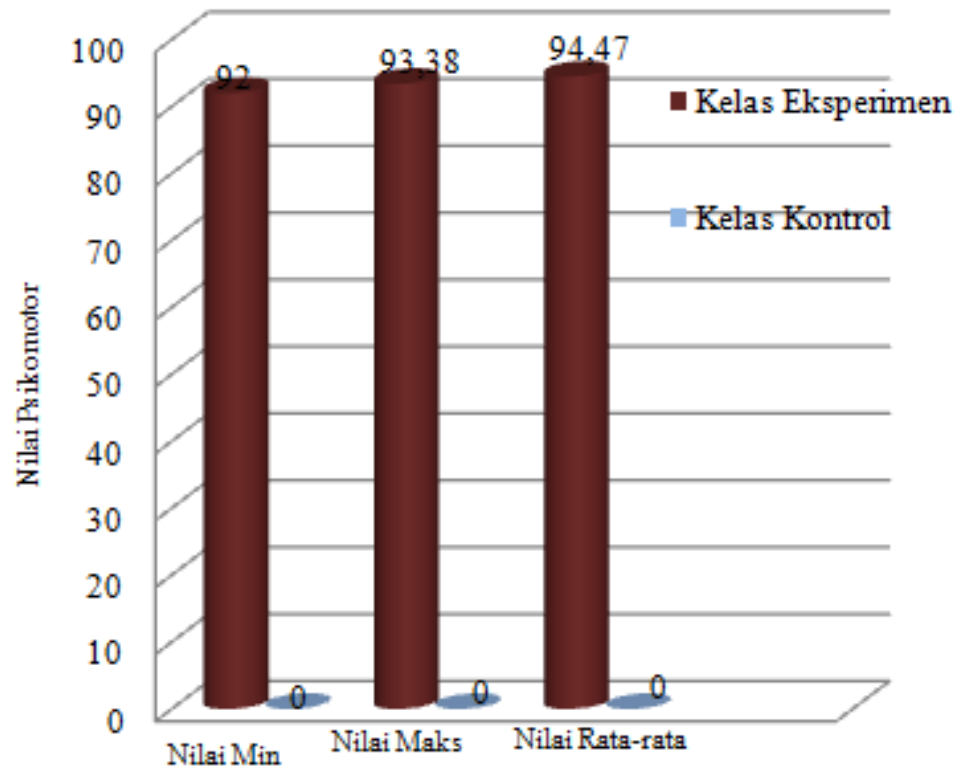

Gambar 3. PerbandinganNilai PsikomotorKelas Eksperimen dan Kelas Kontrol

Berdasarkan Gambar 3 di atas, terlihat bahwa nilai psikomotor kelas eksperimen jauh lebih tinggi daripada nilai psikomotor kelas kontrol. Hal ini disebabkan pelaksanaan pembelajaran di kelas eksperimen lebih didominasi oleh kegiatan siswa di mana siswa diberikan kesempatan langsung untuk melakukan penyelidikan sehingga siswa memperoleh keterampilan dalam melakukan eksperimen tentang materi kalor yang terkait dalam kehidupan sehari-hari. 
Berbeda dengan kelas kontrol yang tidak memperoleh keterampilan sebab pembelajarannya didominasi oleh guru sehingga siswa hanya mendengarkan dan mencatat penjelasan guru saja. Representasi hasil belajar ranah afektif kelas eksperimen dan kelas disajikan pada Gambar 4.

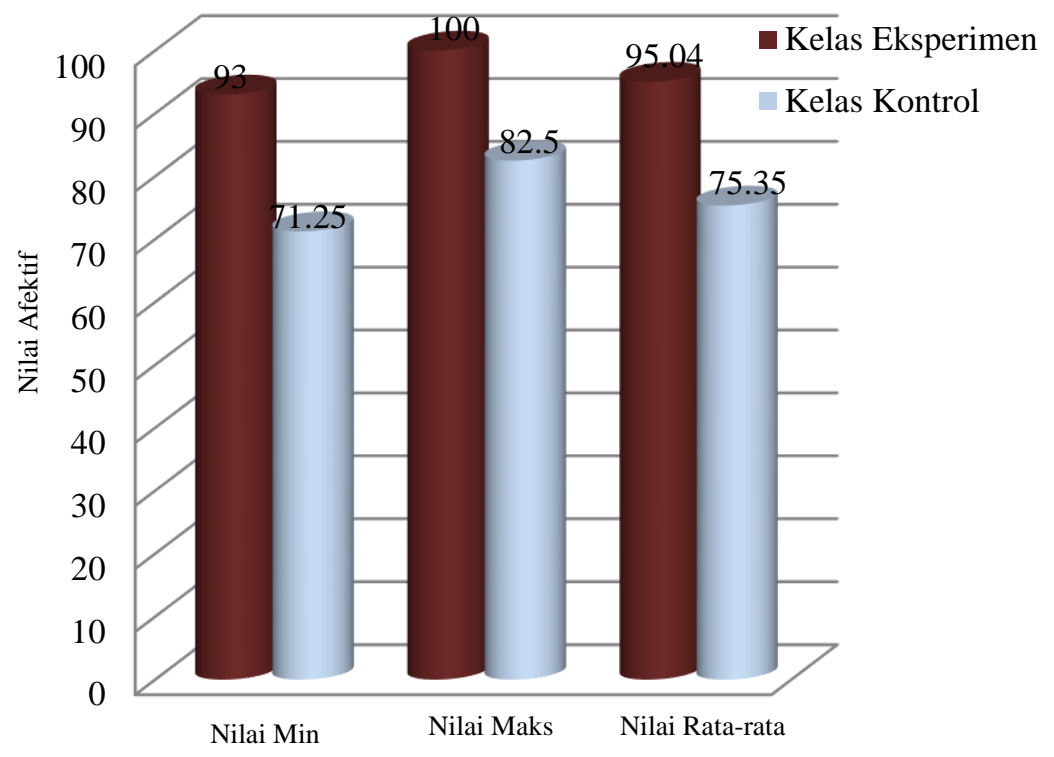

Gambar 4. Perbandingan Nilai Afektif Kelas Eksperimen dan Kelas kontrol

Berdasarkan Gambar 4 di atas, terlihat bahwa nilai afektif kelas eksperimen lebih tinggi daripada nilai afektif kelas kontrol sebab pembelajaran pada kelas eksperimen melalui tahapantahapan yang sistematis dan pembelajarannya lebih didominasi kegiatan siswa sehingga lebih banyak waktu untuk melatih siswa dalam bersikap terhadap teman maupun guru.

Pelaksanaan pembelajaran dengan model CTL berbantuan LKS tentunya tidak terlepas dari hambatan yang dapat mempengaruhi hasil belajar siswa yang meskipun mengalami peningkatan namun tergolong masih rendah. Hambatan-hambatan tersebut berkaitan dengan waktu yang terasa masih kurang untuk melakukan kegiatan-kegiatan yang tercantum di dalam LKS dan pengaturan siswa yang masih sulit diatur. Oleh karenanya, perlu mempersiapkan terlebih dahulu alat-alat dan bahan-bahan yang digunakan dalam penyelidikan dan terlebih dahulu menentukan kelompok-kelompok siswa sehingga pemanfaatan waktu dalam pembelajaran lebih efektif dan efesien agar suasana pembelajaran tercipta lebih kondusif sesuai harapan.

Hasil perolehan post-test tersebut memperlihatkan bahwa terdapat pengaruh model pembelajaran CTL berbantuan LKS terhadap hasil belajar siswa, hal ini didukung hasil uji-t yang didapatkan $t_{\text {hitung }}>t_{\text {tabel }}(3,78>2,01)$.

\section{KESIMPULAN}

Berdasarkan hasil penelitian dapat disimpulkan bahwa terdapat pengaruh model pembelajaran CTL berbantuan LKS terhadap hasil belajar fisika siswa kelas X SMA Attohiriyah Bodak tahun pelajaran 2015/2016, artinya model pembelajaran CTL berbantuan LKS lebih efektif dari pada pembelajaran konvensional.

\section{SARAN}

Penelitian ini dapat menjadi rujukan para guru atau peneliti lain untuk mengimplementasikan model pembelajaran Contextual Teaching and Learning (CTL) berbantuan LKS dalam meningkatkan hasil belajar. Penelitian selanjutnya perlu dilakukan untuk mengeksplorasi efek model pembelajaran CTL terhadap hasil belajar lain (afektif dan psikomotor) dan juga hasil belajar yang lebih spesifik, misalnya keterampilan-keterampilan berpikir. 


\section{DAFTAR PUSTAKA}

Badan Standar Isi. (2006). Standar kompetensi dan kompetensi dasar SMA/MA. Jakarta: Badan Standar Nasional Pendidikan.

Gafrani, N. W., \& Mulyanratna, M. (2013). Penerapan pembelajaran kontekstual berbasis lingkungan dengan keterampilan proses terhadap hasil belajar siswa kelas XI pada materi fluida statis di SMA Negeri 2 Tanggul-Jember. Jurnal Inovasi Pendidikan Fisika, 2(3), 44-49.

Hayati, M. N., Supardi, K. I., \& Miswadi, S. S. (2013). Pengembangan pembelajaran IPA SMK dengan model kontekstual berbasis proyek untuk meningkatkan hasil belajar dan keterampilan proses sains siswa. Jurnal Pendidikan IPA Indonesia, 2(1), 53-58.

Johnsons, E.B. (2014). Contextual teaching and learning: Menjadikan kegiatan belajar-mengajar mengasyikkan dan bermakna. Bandung: Kaifa.

Sugiyanto. (2010). Model-model pembelajaran inovatif. Surakarta: Yuma Pustaka.

Setyosari, P. (2010). Metode penelitian pendidikan dan pengembangan. Jakarta: Kencana Prenada Media Group.

Trianto. (2010). Mendesain Model pembelajaran inovatif-progresif konsep, landasan, dan implementasinya pada Kurikulum Tingkat Satuan Pendidikan (KTSP). Jakarta: Kencana. 